\title{
Culturally Responsive Instruction Leaves No Child Behind: The Story of Juan, a Pacific Island Special Needs Student
}

\author{
Catherine Eileen Stoicovy \\ Richard Fee \\ Julie Fee \\ University of Guam
}

U. S. A.

ABSTRACT: The purpose of this qualitative case study is to explore the use of retelling as a culturally responsive literacy strategy for Juan, a Pacific Island (Chamorro) special needs student on the island of Guam. Data were collected from the following sources: (1) participant-observation (2) fieldnotes (3) audiotaped recordings of students' oral retellings (4) audiotaped interviews with students (5) audiotaped interviews with classroom teacher, and (6) samples of students' written retellings. Results of the study suggest that retelling helps to bridge the dissonance between home and the school. Retelling, congruent with the Chamorro tradition of storytelling, is a natural way of learning for Chamorro students. Moreover, retelling in a small group setting is compatible with inafa'maolek, a core value of Chamorro culture that means helping each other in an agreeable fashion. Based on Juan's productive academic performance and appropriate behavior during the retelling sessions, the following two issues warrant consideration: a reevaluation of his diagnosis of ADHD and further exploration of the use of culturally responsive instruction to scaffold his academic performance.

Guam, Colonial History, and Education Culturally Responsive Instruction and Special Education Retelling as a Culturally Responsive Instructional Strategy Method Juan: A Chamorro $5^{\text {th }}$ Grader Analysis of Retelling Final Thoughts: ADHD or Misdiagnosis? References

Appendix A: Interview Questions for Teachers Appendix B: Literacy Interview Questions Appendix C: Retelling Interview Questions Appendix D: The Legend 


\section{Guam, Colonial History, and Education}

In 2002 The No Child Left Behind Act (NCLB) emphasized the need to close the achievement gap between high and low performing children, especially the achievement gap between minority and non-minority students and between disadvantaged children and their more advantaged peers. A decade later, the achievement gap still exists. Closing the gap requires more than just addressing cognitive challenges. One way to bring students of diverse backgrounds to higher levels of academic performance is through the use of culturally responsive instruction (Au, 2011; Gay, 2010; Ladson-Billings, 2009; Nieto, 2009). In this study we explore how the use of the retelling strategy as a culturally responsive literacy strategy allowed Juan, a $5^{\text {th }}$-grade Pacific Island (Chamorro) special needs student on Guam diagnosed with Attention Deficit Hyperactive Disorder (ADHD), to achieve literacy at a higher level than his diagnosed level.

The Chamorro people are the indigenous inhabitants of Guam and the other Mariana Islands, who came to these Western Pacific islands over 4,000 years ago and were part of the migration in the Pacific from Southeast Asia. Anthropologists believe that the ancient Chamorros came from Southeast Asia because of physical and cultural similarities between the people of the Mariana Islands and the people of Coastal Southeast Asia, Indonesia, and the Philippines (Carano \& Sanchez,1964; Cunningham, 1992).

Education on the island of Guam cannot be understood without first examining the influences of the colonial powers in Guam's history. The United States education system is the current model used on Guam; however, other colonial powers have also impacted education on the island. Spain claimed Guam in 1598 and stayed until 1898. A major focus of the Spanish colonial rule was the conversion of the Chamorros to Roman Catholicism. Spanish priests on the island held most of the responsibility for educating the Chamorros. Although they provided the people with only a rudimentary education, they were instrumental in perpetuating the Chamorro language by permitting and encouraging its use in the Church. Spanish rule lasted until 1898 when the United States acquired Guam after defeating Spain in the Spanish-American War. During the brief pre-war years of 1899-1941, a new form of colonialism was established with the introduction of American culture to the island. Schools were established to teach the Chamorros basic education skills. This brief period of American rule was interrupted when Japan invaded Guam in December 1941 and occupied the island until 1944. During the occupation, the Japanese imposed their language and culture, and Japanese became the language of the schools. In 1944 the U.S. military liberated Guam from the Japanese and established compulsory education and an English-only policy in the schools and the workplace. The Church was no longer instrumental in preserving the Chamorro language. Economic necessity was a compelling reason for Chamorros to assimilate the American culture and to speak the English 
language. Today the official languages of Guam are English and Chamorro. Both languages are taught in schools and appear in official documents; however, English is the language of instruction in the schools.

The Guam Department of Education (GDOE) schools educate a multicultural mix of students with diverse academic, cultural, and linguistic backgrounds and needs. Table 1 depicts the distribution of GDOE students by ethnicity according to the GDOE Annual State of Public Education Report SY2010-11 (Taitano, 2011).

Table1. SY 2010-11 Distribution of Students by Ethnicity

\begin{tabular}{|l|r|r|}
\hline \multicolumn{1}{|c|}{ Ethnicity } & Number of students & Percent of total \\
\hline Chamorro & 15,116 & $49 \%$ \\
\hline Filipino & 6,891 & $23 \%$ \\
\hline Pacific Islander & 7,038 & $23 \%$ \\
\hline Asian & 488 & $2 \%$ \\
\hline $\begin{array}{l}\text { Commonwealth of Northern Marianas } \\
\text { (CNMI) }\end{array}$ & 412 & $1 \%$ \\
\hline White Non-Hispanic & 229 & $1 \%$ \\
\hline Other & 194 & $1 \%$ \\
\hline Unaccounted & 233 & $1 \%$ \\
\hline TOTAL & 31,095 & $100 \%$ \\
\hline
\end{tabular}

Of the 31,095 students enrolled in the Guam Department of Education, at least 21 ethnic groups are represented. The CNMI includes students from Rota, Saipan, and Tinian. Asians consist of Japanese, Chinese, Korean, Indonesian, and Vietnamese ethnic groups. Pacific Islander includes Hawaiian, Kosraean, Samoan, Pohnpeian, Chuukese, Yapese, Marshallese, Palauan, and Fijian. Other is comprised of African-American, Hispanic, American Indian-Native Alaskan, and unknown and unclassified categories. The "Unaccounted" represents students who did not officially report their ethnicity information.

Adding to the diversity is the number of special needs students. Of the 31,095 students enrolled in GDOE schools, 10,300 are enrolled in one or more special programs such as special education, English Language Learners, and other programs that provide special services to students. The special education program comprises $20 \%$ of the 10,300 students. A number of students with disabilities spend part or all of their school day in a general education classroom. According to GDOE, there is a need to improve the academic achievement of Guam public school students, including those with special needs. Of the 1,641 
students who graduated from GDOE schools last year, only 12\% were proficient in reading, $6 \%$ were proficient in language, and only $1 \%$ proficient in math.

\section{Culturally Responsive Instruction and Special Education}

Closing the achievement gap for all students requires more than just addressing cognitive challenges. To bring students of diverse backgrounds to high levels of literacy will also require the use of culturally responsive instruction. According to $\mathrm{Au}$ (2011), culturally responsive instruction has the goal of helping students grasp academic concepts through means and content responsive to their cultural values and practices. Based on the premise that culture is central to student learning, culturally responsive pedagogy builds on the student's cultural knowledge, prior experiences and performance styles to improve academic learning (Stoicovy, 2006). A review of the literature suggests that providing instruction that is culturally responsive promotes high achievement among culturally and linguistically diverse students (Au, 2011; Gay, 2010; Ladson-Billings, 2009; Nieto, 2009).

Gay (2010) defines culturally responsive teaching as using the cultural knowledge, prior experiences, and performance styles of diverse students to make learning more appropriate and effective for them. Cultural incompatibilities are often mistaken for intellectual inability or lack of motivation. For example, failing to understand the difference in communication styles may cause teachers erroneously to conclude that students have limited critical thinking and reasoning abilities. Some cultural groups may not speak out or openly challenge their teacher with questions. They will remain quiet if a question is directed to them, even if they know the answer. Teachers instructed in the Anglo-European style of extensive questioning techniques in their classrooms often conclude that these students are shy or do not understand the question (Stoicovy, 2004). Moreover, some students may prefer to learn in cooperation with peers while the learning style of others is to work independently. To maximize learning opportunities, it is important that teachers gain knowledge of the cultures represented in their classrooms and translate this knowledge into instructional practice, helping students find relevant connections among themselves and with the subject matter and the tasks teachers ask them to perform (Montgomery, 1997).

Culturally responsive instruction also applies to special education because the Individuals with Disabilities Education Act (IDEA, 2004) supports the provision of culturally responsive instruction for special needs learners in mainstreamed environments, especially diverse learners over-represented in special education programs. The disproportionate representation of culturally and linguistically diverse students in special education programs has been a concern for more than three decades (Klingner et al., 2005). Several factors contribute to the disproportionate representation, such as teachers' lack of knowledge about culturally and linguistically diverse children and their tendencies to label the behavior of these students as negative and inappropriate (Klingner et al., 2005). 
According to Harry and Klingner (2006), the combination of interpreting behaviors through one set of cultural lens and instructional practices contributes to disproportionality in special education. The failure of teachers to use culturally responsive instructional practices can exacerbate the problem. Proponents of culturally responsive instruction support the notion that the disproportionate representation will be reduced if more students receive culturally responsive instructional practices, thereby reducing the cultural incompatibilities between the home and school.

Teachers often have limited ideas about diversity and special needs (Kea; Campbell-Whatley; \& Richards, 2006). Despite the diversity and special needs found in today's classrooms, not all teacher education programs readily embrace multicultural education or culturally responsive teacher education pedagogy (Gay, 2000). A major part of the resistance comes from teacher educators' discomfort, if not fear of, addressing issues such as race and racism in their courses or even on their campuses (Cochran-Smith, 2004). Some schools of education have acknowledged the need for developing culturally competent teachers, while others struggle to fit appropriate programs into their curriculum. Many teachers are faced with limited understanding of the cultures and special needs of students other than their own and of the possibility that this limitation will negatively affect their students' ability to become successful learners. Hence, teachers must critically assess their understanding of students' cultures (Schmidt \& Lazar, 2011). In this study we made an effort to demonstrate how a cultural understanding of Chamorro culture regarding storytelling may be implemented in instruction in the form of retelling.

\section{Retelling as a Culturally Responsive Instructional Strategy}

Retelling is an instructional strategy whereby readers or listeners tell what they remember from a reading, either orally or in writing or illustration (Kalmback, 1986). When used in all its forms, retelling offers natural opportunities for children to grow as language users, in that all the traditional language arts - listening, speaking, reading, and writing - are involved in a collaborative way (Brown \& Cambourne, 1990). Retelling encourages children to incorporate the vocabulary, sentence patterns, and writing conventions of the text into their own writing. Brown and Cambourne coined the term "linguistic spillover" to describe the reappearance of certain linguistic forms, structures, concepts, and conventions which had been encountered in the texts used in retelling sessions. Sometimes the spillover appeared weeks or months later. It was clear evidence that internalization had taken place. They considered this an important discovery because they realized that they could maximize the probability of certain kinds of text features being learned if the retelling pieces were chosen appropriately. The internalization of the text revealed itself in two ways. First, children's written retellings contained many of the features of the original text. They contained some or all of the events, characters, and other aspects of the meanings in the 
original text. Furthermore, some of the same phrases and vocabulary found their way into the written retellings. Certain textual features, such as the use of colons, the separation of speech from other parts of the text, or the spellings of words that the students had never used before, were also appearing in the written retellings. Brown and Cambourne called this direct spillover, whereas those text features that find their way into other writing the children are doing, sometimes a considerable time after the actual retelling takes place, were described as delayed spillover. These text features include words, phrases, ideas, rhetorical devices, organization of content, as well as spelling and punctuation marks.

For assessment purposes, retelling can be a valuable diagnostic tool. Lipson and Wixson (2008) have found that retelling reveals a wealth of information about a child's comprehension. It shows what a child comprehends, as well as how the child comprehends. It can reveal children's awareness of text structure, their language proficiency, and their ability to identify important aspects of the material. In addition, retellings are valuable in providing insights into children's metacognitive strategies, the strategies that readers use consciously or unconsciously to understand what they are reading. Retellings can be used to measure a reader's or writer's strengths and weaknesses and to identify the kinds of reading materials and level of difficulty most appropriate for them. When used in a pre/post situation, retelling can also be used to measure growth in reading, oral language and writing. These measures show us what the child can do. This information is in contrast with many tests, which point out what children cannot do.

The retelling strategy provides a holistic representation of student understanding rather than the fragmented information provided by answering comprehension questions. As Rosen (1986) tells us, the human brain is essentially a narrative device that runs on stories. The knowledge that we store in the brain as part of our theory of the world is largely in the form of stories, which are far more easily remembered and recalled than sequences of unrelated facts (Smith, 1990). Because text recall through retelling is natural for children, it does not necessarily bias them to process text in a particular way, as questions do (Lipson \& Wixson, 2008). Additionally, stories are an important tool for proclaiming ourselves as cultural beings (Dyson, 1994). "In narratives, our voices echo those of others in the sociocultural world. That is, we evidence cultural membership both through our ways of crafting stories and in the very content of our tales" (p. 4).

Retelling is culturally congruent with the Chamorro tradition of storytelling. According to local historians (Beardsley, 1964; Cunningham, 1992), the ancient Chamorros were fond of festive dancing and singing, storytelling, and legendspinning. There were festivities where the people sang or recited legends and stories of their ancestors. The best storytellers competed to see who could speak or sing the most couplets in long epic poems. Storytelling continues to be a significant part of the Chamorro culture. Emphasis is on the spoken or sung word, wherein stories are told to living audiences and remembered through their 
retellings rather than through reading and writing as in a literate culture (Stoicovy, 2004). Stoicovy explains that the degree to which they are influenced by patterns of literate thought will vary; however, their cultural roots remain grounded in the traditions of orally held knowledge. Legends, fables, and family history come alive as islanders, both young and old, retell special stories passed down from their elders. Since storytelling is an integral part of Chamorro culture, the retelling strategy seemed to be a good fit for Juan, a $5^{\text {th }}$-grade Chamorro special needs student and the focus of this study, as retelling builds on the oral strengths that he brought to the classroom. Additionally, because small group retelling provides a collaborative setting to practice verbal discourse and recall of text, the oral retelling sessions could provide a means of developing literacy that is compatible with the Pacific Island spirit of cooperativeness and collaboration known as inafa'maolek. A core value in Chamorro culture, inafa'maolek, means making it good for each other or helping each other in an agreeable fashion (Cunningham, 1992). Inafa'maolek is a sense of mutuality and togetherness. Shared work requires cooperation within the group and always accomplishes more than individual work. Retelling in small groups would provide a setting conducive for Juan and his peers to work together in the spirit of inafa'maolek.

\section{Method}

According to Creswell (2006), a case study is an appropriate method to use when the purpose of the investigation is to provide a rich, intensive description of a single entity and the phenomena surrounding it. As Creswell (2008) explains, the researcher in qualitative inquiry is the primary instrument for data collection and the analyst who collects the detailed views of participants in the form of words or images and analyzes the information for description and themes.

In keeping with qualitative research tradition, the study employed purposeful sampling methods. When developing a purposive sample, researchers use their special knowledge or expertise about some groups to select subjects who represent this population (Berg \& Lune, 2011). Out of four $5^{\text {th }}$-grade Chamorro students in an elementary classroom on Guam, we focused on Juan in this study because we wanted to explore the use of retelling as a culturally responsive literacy strategy for a Chamorro special needs student. Interviews were conducted with the classroom teacher to provide further insights about Juan. Consistent with the features of qualitative case study design, data were collected from the following sources: (1) participant-observation (2) fieldnotes (3) audiotaped recordings of students' oral retellings (4) audiotaped interviews with students (5) audiotaped interviews with classroom teacher, and (6) samples of students' written retellings. All data have been kept confidential. Pseudonyms are used throughout the process to ensure anonymity.

Juan participated in one-hour retelling sessions two times per week for four months with three of his classmates, also Chamorro Pacific Islanders who, 
like Juan, were struggling readers and writers. Brown and Cambourne (1990) recommended that teachers introduce the retelling strategy with a familiar text, so I selected favorite island legends and other tales for the students to read and retell to one another. The stories would facilitate text recall because they build on the students' cultural and linguistic background and familiarity with text structure. What learners already know about the events, ideas, and objects described in a text influences meaning they construct from that text. Familiarity with the content and structure of a text can offset reading comprehension difficulties. To the extent that readers have prior knowledge of a particular text, their comprehension task will be more or less difficult (Stoicovy, 2004).

Below are the instructions the researcher was given to implement the retelling sessions in the original study:

1. Tell the students that you are going to read aloud the legend and that you want them to listen very carefully.

2. After the read aloud, distribute individual copies of the legend and ask students to read and retell to one another. Tell them:

Students, now I want you to practice reading and retelling the legend to one another. Retelling is a good way to help you remember and understand what you read or what is read to you. Take turns reading aloud to each other before retelling the legend. The listeners give feedback by adding anything important that the reteller has left out. Do not interrupt the reteller while he/she is retelling. Wait until after the reteller has completed the retelling to provide constructive feedback.

3. When students have finished retelling to one another, gather the individual copies from each of them.

4. Instruct students to take out a sheet of paper. Ask them to write their name and date at the top of the paper. Then ask them to write the title of the legend and to write as much as they can recall about the legend. Remind them that this is not a summary, but rather a retelling that starts from the beginning to the end of the story

\section{Juan: A Chamorro $5^{\text {th }}$ Grader}

Juan is an indigenous Chamorro, born and raised on Guam. He speaks proficient English and Chamorro at a rudimentary level. Both Chamorro and English are spoken in the home. According to school records, Juan was diagnosed with ADHD during his third grade year. Character development grades throughout his elementary years indicate a need for improvement in selfcontrol. Written comments from his fourth grade teacher describe Juan as "impulsive, easily distracted and loud when interacting with others." His current teacher, Ms. Cruz, reports that Juan's impatience causes him to rush and produce work that is not to his full potential. He is not under medication for 
ADHD. The school's goals are to help Juan develop the ability to control his behavior, so that one-on-one supervision can be phased out, and to improve his academic performance. According to Ms. Cruz, Juan has difficulty with reading and writing, which also impacts all of the other academic subjects. He shows little interest in reading and has difficulty comprehending text. He is able to retell the broad sense of text but lacks continuity and detail.

Results of the Qualitative Reading Inventory (Leslie \& Caldwell, 2010), an informal reading inventory administered by the researcher, indicate that Juan is reading below grade level. He gets frustrated with word recognition and comprehension at the fourth grade level, which indicates that the material is too difficult for him to read and understand. Miscue analysis results on the word lists reveal that a majority of his miscues are graphically similar in the initial letters only, suggesting that he relies on the initial letters to guess at the word. Juan performs better at word recognition in the QRI passages. When he encounters unknown words in the passages, he makes a stab at using syntactic and semantic cues to identify the words. Juan has a difficult time answering both literal and inferential questions on topics for which he has little-to-no background knowledge. He performs much better on familiar passages and those of interest to him. The retelling component of the QRI assessments shows that Juan can retell narrative passages more easily than expository, which is consistent with Brown and Cambourne's (1990) assertion that children generally have an easier time retelling narrative text because they are more familiar with the text structure. However, Juan's retellings of both types of text are generally skeletal with only the barest of details. He also has difficulty with writing. Ms. Cruz describes him as a struggling writer who has difficulty getting ideas onto paper. His ideas are not well developed or cohesive, and he uses few conventions appropriate to grade level. Furthermore, Juan does little editing to the content of his writing; changes made are to handwriting or spelling only.

The researcher conducted a literacy interview with Juan to determine how he perceives himself as a reader and a writer. An analysis of his responses reveals that Juan thinks of reading as correct pronunciation. He describes a good reader as someone who "knows how to pronounce every word." His responses bore no connection to reading as a meaning-making process. Juan identified his classmate Jose as a good reader "because Jose knows all the words on the page." When asked how he perceives himself as a writer, Juan's responses were quite telling. As with many struggling writers, Juan focuses heavily on form, rather than content (Strickland, Ganske, \& Monroe, 2002). It is obvious that he equates good writing with neat penmanship. He describes himself as a poor writer because of poor penmanship. "I've seen my writing," he explains with a serious tone of voice. "My penmanship is not so good. I need to practice it." Juan thinks his best friend Pedro is a good writer. "Pedro always gets A's for penmanship on his report card," he tells me with excitement. "I want to get A's, too," he adds. Because an overemphasis on form can become an obstacle to getting ideas onto paper, it was important to move Juan beyond his anxiety about penmanship, to caring about the content of his writing. 
Diagnosed with ADHD, Juan is further disadvantaged by disability-related needs associated with the diagnosis. ADHD is one of the most common childhood disorders and can continue through adolescence and adulthood. Symptoms include difficulty staying focused and paying attention, difficulty controlling behavior, distractibility, and hyperactivity. It is estimated that between 3 and 5 percent, or approximately 2 million children in the United States, have ADHD. According to the National Institute of Mental Health (2008, p. 1), "This means that in a classroom of 25 to 30 children, it is likely that at least one will have ADHD."

\section{Analysis of Retelling}

The process of data analysis in qualitative research is a matter of reduction and interpretation (Creswell, 2006). The researchers in this study went through all of the data, examining emerging patterns and organizing them into clusters according to similarities. Patterns that did not fit into a cluster and were not substantiated by triangulation were omitted as potential themes.

\section{Retelling as a Scaffold for Writing}

Getting students to write can be a challenge for any classroom teacher. The seemingly simple task of putting pencil to paper can be a daunting experience for the writer. Therefore, I selected a Chamorro legend that Juan and his retelling partners were familiar with, titled "Why the Iguana Has a Double Tongue" (Guam Department of Education, 1981: see Appendix D for a copy of the legend). After participating in one group session which involved oral retelling of the legend, Juan was able to produce the following individual written retelling:

The Legend Of Why The Iguana Has A Double Tongue

Many, many years ago in a deep dark cave in the dence of the junle of guam there lived an iguana. This the iguana's mother was very proud of him. after all he was strong and handsome. after many month's of mothering, caring, and teaching he was allowed to go into the junle to look for bird eggs. all iguana love eggs. while walking the iguana heard a muaking bird. he said hello where are you. the bird did not answer this dissappointment the iguana continued on his merry way. not long before the iguana met the muaking bird know as the rail. they became friends and they both decided to make more colors on there skin. after some bright colors the iguana was pleased with his appearan's. he sang loud and beautiful voice. he took the same paint he was painted with and splatted the rail and he was very angry so he said for this you have played a tricks on me. so I will make your pretty voice harie and ugle So he stepped on the iguana tongue. so til this day you see that the iguana has two tongues and the rail has spots all over it. 
At first glance, the errors in sentence structure, misspellings and other mechanics immediately stand out in the retelling. A closer review, however, shows that despite the syntactical and mechanical errors, the retelling reveals a fairly accurate account of the legend. A comparison of the original text with Juan's written retelling shows that he has comprehended the legend and retold, in various degrees of completeness, the story from beginning to end. Moreover, he has internalized some of the rich vocabulary of the author, using phrases from the legend such as: "Many, many years ago in a deep dark cave in the dence of the junle of guam there lived an iguana.," and "so til this day you see that the iguana has two tongues and the rail has spots all over it." The linguistic spillover found its way into Juan's writing and will help him to overcome limitations in expressive abilities in terms of vocabulary, syntax, and idiomatic expressions (Peregoy \& Boyle, 2008; Stoicovy, 2004). That Juan exhibited no anxiety about incorrect spellings and imperfect penmanship is an indication that he is able to move beyond an overemphasis on writing mechanics to caring about the content of his writing. Refinement of content and mechanics can be addressed during the writing process, from first draft to final copy.

\section{Retelling as a Scaffold of Text Recalling}

Small group retelling provided Juan and the group with a collaborative setting to practice verbal discourse and recall of text that is compatible with Chamorro Pacific Island culture. For example, when I interviewed Juan, he explained how retelling helped him produce a written retelling of the legend:

Researcher: When you put your pencil to the paper, what happens?

Juan: It feels like magic, for example it just like all comes out.

Researcher: Do you remember what people said during the oral retelling? Juan: Yes.

Researcher: Tell me about that.

Juan: Like for example, those are my imaginary friends. Like all recorded in my head.

Researcher: It's all recorded in your head? What was recorded?

Juan: The story that I told and heard. A magic tape recorder.

When asked if they enjoy retelling stories in a small group setting, Juan and his retelling partners responded as follows:

Researcher: What do you like about retelling stories in a small group?

Juan: It's fun, because everyone's in a group. We're all forgetting, but we're all helping each other. 
Antonio: We get to use part of everyone's story.

Dolores: You stay in a group and talk about your stories. It's fun. You won't be lonely doing your work.

Benigno: We all get to try and we're not fighting over it. You know how there's some people who complain "It's not your turn, it's my turn, it's not your turn." Always fighting about it. But when it's only three or four people, then we just take our turns, first, second, third. We just made up our minds without arguing.

Researcher: Do you like working together cooperatively?

Benigno: Yes.

Juan: When we read it together, we take turns, we tell it out, we write it. That's how we remember it.

Juan's comments suggest that he profits from cooperative work and enjoys the small group setting. Moreover, oral retelling serves as Juan's magic tape recorder to record in his mind the story that he heard and told so that he could then reconstruct it both verbally and in writing. Oral retelling served as a literacy scaffold or temporary support for Juan. Peregoy and Boyle (2008) define literacy scaffolds as instructional strategies that help students write or comprehend whole, meaningful texts at a level somewhat beyond what they could do on their own. Just as scaffolding is temporarily provided to help workers construct a building, literacy scaffolds provide temporary frameworks until the student is able to accomplish the task independently (Vygotsky, 1978).

The collaborative setting served as a literacy scaffold in other ways as well. For example, the following conversation between the students during a retelling session of "Why the Iguana Has a Double Tongue" reveals how Juan and his peers built on their prior knowledge to connect text with life experiences and cultural background:

Juan: Why are they (rails) extinct?

Benigno: Their eggs are eaten by the brown tree snakes. When my dad catches a snake he cuts off its head. He grabs it by the neck. First he blinds the snake's vision with a flashlight and then cuts off its head.

Benigno: Once my cousin was riding a dirt bike when he suddenly yelled out STOP! He swerved and a rail flew away.

Juan: How come a snake has two tongues like an iguana?

Antonio: Yeah, it has a tongue like an iguana.

Dolores: Maybe the rail cut its tongue.

The relevant content helped Juan and his peers to construct relationships between existing schemata and the information in the text, thus contributing to their understanding of the legend. Although all readers use information from the 
text for their retellings, the retellings can differ greatly. The differences among retellings stem from varying schemata and experiences brought to the reading. The more relevant the story is to the reader, the more accurate the retelling.

The following conversation and observations reveal yet another scene in which Juan demonstrates his ability to work with his group members. Juan and his peers are retelling a favorite tale titled "The Old Lady in the Vinegar Bottle," from Brown and Cambourne's book Read and Retell (1990).

Juan: Okay whose turn?

Antonio: Your turn.

(Juan begins to retell)

Antonio: Juan, you're supposed to start from the beginning.

(Juan starts from the beginning but stumbles when he can't recall some words)

Juan: And a kind fairy came to um. . um. . .um. . .

Dolores: Visit her! (Dolores says this in a teasing, playful way).

Juan: Shhhh.

Antonio: (smiles at Juan).

Dolores: (with a big smile, leans over to Juan as he continues to retell).

Antonio: You forgot the palace part.

Juan: continues to retell... then stumbles somewhat saying umm . . . umm. . . . umm ... so she umm . . . so she a. . . your turn, Antonio!

Antonio: (chuckling) So what was the end of the story?

Juan: Close your eyes three times and then she found herself in a castle.

Antonio: You have to say with a crown.

Juan: With a crown on her head and splendid clothes and a land to rule. So many months later she came to visit the old lady and the old lady said, "What a shame what a shame, why do I have to live in a little castle and rule little land when I can rule the whole world?" So she (fairy) was very angry and she said close your eyes and this the crone did and when she closed her eyes she found herself back in the vinegar bottle.

Juan: Finished! I finished the whole thing!

Dolores: (says excitedly) He finished the whole story!

With support from his peers, Juan successfully completes his retelling without incident. Once again, the children work together harmoniously in a collaborative setting. 


\section{Final Thoughts: ADHD or Misdiagnosis?}

ADHD and its diagnosis and treatment have been considered controversial since the 1970s (Parrillo, 2008). ADHD requires an observer's interpretation, and many children will occupy what Parens \& Johnston (2009) refer to as a zone of ambiguity. Furthermore, males are approximately 2-4 times more likely to be diagnosed with ADHD as compared to females (NIMH, 2006; Singh, 2008). Studies suggest this discrepancy may be partially due to subjective bias of the referring teachers (Sciutto, Nolfi, \& Bluhm, 2004) with females tending to have more of the inattentive symptoms as opposed to the hyperactive and impulsive symptoms that are more disruptive, thereby receiving more attention. Another reason for the controversy is that minority status has been associated with a higher prevalence of ADHD. For example, in the United States African American children, especially boys, are at increased risk for being diagnosed with a hyperactivity disorder and placed in special education but lack the same access to treatment as their White counterparts (Maddox, 2003).

As for Juan, based on his productive academic performance and appropriate behavior during the retelling sessions, the following two issues warrant consideration: a reevaluation of his diagnosis of ADHD and further exploration of the use of culturally responsive instruction to scaffold his academic performance.

Was Juan accurately diagnosed with ADHD? Contrary to a history of disruptive behavior throughout his school years, Juan stayed on task and did not disrupt the group during the retelling sessions. Throughout the study, Juan maintained a productive role during the sessions, even without the supervision of the paraprofessional. He was appropriately engaged and worked cooperatively with his retelling partners. His performance reflected a more optimistic picture of his literacy skills than his teacher's assessment would suggest. At the start of the study, Ms. Cruz described Juan as a struggling writer who has difficulty getting ideas onto paper. Juan's retellings of the legend "Why the Iguana Has a Double Tongue" produced during the study revealed otherwise. His oral and written retellings reflected comprehension of text, linguistic spillover, and story structure and show promise for improvement with more practice. Given his performance, it is safe to say that the school should consider a reevaluation of Juan's diagnosis.

Was the retelling strategy a factor in Juan's academic performance and appropriate behavior? In the culture of the school, language is not used primarily as a means of face-to-face communication, but rather as a tool for abstract learning, for developing and expressing one's thoughts through reading and writing. For the Chamorro child, this poses a mismatch or cultural incongruence between the culture of the home and the culture of the classroom, which often leads to difficulties in academic success. Retelling appears to be a culturally responsive strategy that helps to bridge the dissonance between home and the school. Since a key element of the Chamorro culture is orality, retelling is a natural way of learning for Juan. Moreover, retelling in a small group setting is 
compatible with inafa'maolek, a core value of Chamorro culture. Retelling with his peers provided Juan with a supportive, collaborative setting to practice verbal discourse and recall of text in the spirit of inafa'maolek.

Through the use of culturally responsive instruction and improved ways to diagnose ADHD, we may be one step closer to closing the achievement gap between disadvantaged children and their more advantaged peers so that no child will be left behind.

\section{References}

Au, K. (2011). Literacy achievement and diversity: Keys to success for students, teachers, and schools. New York, NY: Teachers College Press.

Beardsley, C. (1964). Guam past and present. Tokyo, Japan: Charles E. Tuttle.

Berg, B., \& Lune, H. (2011). Qualitative research methods for the social sciences. Upper Saddle River, NJ: Prentice Hall.

Brown, H., \& Cambourne, B. (1990). Read and retell. Portsmouth, NH: Heinemann.

Carano, P., \& Sanchez, P. (1964). A complete history of Guam. Rutland, VT: Tuttle.

Cochran-Smith, M. (2004). Walking the road: Race, diversity, and social justice in teacher education. New York, NY: Teachers College Press.

Creswell, J. (2006). Qualitative inquiry and research design: Choosing among five approaches. Thousand Oaks, CA: Sage.

Creswell, J. (2008). Research design: Qualitative, quantitative, and mixed methods approaches. Thousand Oaks, CA: Sage.

Cunningham, L. (1992). Ancient Chamorro society. Honolulu, HI: Bess Press.

Dyson, A. (1994). The need for story: Cultural diversity in classroom and community. Urbana, IL: National Council of Teachers of English.

Gay, G. (2000). Culturally responsive teaching: Theory, research, and practice. New York, NY: Teachers College Press.

Gay, G. (2010). Culturally responsive teaching: Theory, research, and practice $\left(2^{\text {nd }}\right.$ ed.). New York, NY: Teachers College Press.

Guam Department of Education (1981). Legends of Guam. ESAA Project. Chamorro Language and Culture Program, Agana, Guam.

Harry, B., \& Klingner, J. (2006). Why are so many minority students in special education? Understanding race and disability in schools. New York, NY: Teachers College Press. 
Kalmback, J. (1986). Getting at the point of retellings. Journal of Reading, 29, 326-333.

Kea, C., Campbell-Whatley, G., \& Richards, H. (2006). Becoming culturally responsive educators: Rethinking teacher education pedagogy. National Center for Culturally Responsive Educational systems (NCCREST). Retrieved from http://nccrest.org/Briefs/Teacher Ed Brief.pdf

Klingner, J., Artiles, A. J., Kozleski, E., Harry, B., Zion, S., Tate, W., Zamora Duran, G., \& Riley, D. (2005). Addressing the disproportionate representation of culturally and linguistically diverse students in special education through culturally responsive educational systems. Education Policy Analysis Archives, 13(38). Retrieved from http://epaa.asu.edu/ ojs/article/view/143

Ladson-Billings, G. (2009). The dreamkeepers: Successful teachers of African American children. San Francisco, CA: Jossey-Bass.

Leslie, L., \& Caldwell, J. (2010). Qualitative reading inventory-5. Boston, MA: Allyn \& Bacon.

Lipson, M., \& Wixson, K. (2008). Assessment and instruction of reading and writing disability. An interactive approach. Boston, MA: Allyn \& Bacon

Maddox, C. (2003). Race matters: Disparities in African-American children with Attention Deficit Hyperactivity Disorder. Penn State McNair Journal, 10 (Summer), 145-164.

Montgomery, W. (1997). Creating culturally responsive, inclusive classrooms. Teaching Exceptional Children, 33(4), 4-9.

National Institute of Mental Health. (2006). The numbers count: Mental disorders in America. Retrieved from https://www.disability.gov/viewResource? id=1393 4092

National Institute of Mental Health (NIMH). (2008). Retrieved from http://wwwapps.nimh.nih.gov/health/publications/adhd/introduction.shtml

Nieto, S. (2009). The light in their eyes: Creating multicultural learning communities. New York, NY: Teachers College Press.

No Child Left Behind (2002). Retrieved from http://www.ed.gov/nclb/landing.jhtml

Parens, E., \& Johnston, J. (2009). Child and adolescent psychiatry and mental health. 2009; 3: 1 . Retrieved from http://www.ncbi.nlm.nih.gov/pmcl articles/ PMC2637252/

Parrillo, V. (2008). Encyclopedia of social problems. Thousand Oaks: Sage.

Peregoy, S. F. \& Boyle, O.F. (2008). Reading, writing, \& learning in ESL: A resource book for K-12 teachers. Boston, MA: Allyn \& Bacon.

Rosen, H. (1986). The importance of story. Language Arts, 63, 226-237. 
Schmidt, P. R., \& Lazar A.M (2011). Practicing what we teach: How culturally responsive literacy classrooms make a difference. New York, NY: Teachers College Press.

Sciutto, M. J., Nolfi, C. J., \& Bluhm, C. (2004). Effects of child gender and symptom type on referrals for ADHD by elementary school teachers. Journal of Emotional and Behavioral Disorders 12(4), 247-253.

Singh, I. (2008). Beyond polemics: science and ethics of ADHD. Nature Reviews Neuroscience, 9(12): 957-64.

Smith, F. (1990). Insult to intelligence: The bureaucratic invasion of our classrooms. Portsmouth, $\mathrm{NH}$ : Heinemann.

Stoicovy, C. (2004). Using retelling to scaffold English language learning for pacific island students. The Reading Matrix. An International Online Journal 4(1). Retrieved from http://www.readingmatrix.com/journal.html

Stoicovy, C. (2006). Culturally responsive instruction leaves no child behind. PREL Pacific Comprehensive Center Featured Topics Webinars. Retrieved from http://www.prel.org/featured-topics/webinars.asp

Strickland, D. S., Ganske, K., \& Monroe, J. K. (2002). Supporting struggling readers and writers: Strategies for classroom intervention 3-6. Portland, ME: Stenhouse.

Taitano, T. M. (2011). Guam Department of Education Annual State of Public Education Report SY2010-11. Retrieved from https://sites.google.com/a/ gdoe.net/rpe/home/annual-state-of-public-education-report-asper/sy20102011

Vygotsky, L. S. (1978). Mind in society: The development of higher psychological process. Cambridge, MA: Harvard University Press.

\section{Appendix A}

\section{Interview Questions for Teacher}

I want to thank you for taking time to talk with me today. I will be recording what we say in order to ensure an accurate representation of your responses. It is important that I reflect in my writings what you mean. I will not use your real name, but rather your pseudonym in my written report. This is to protect your anonymity and to stimulate open communication.

You have had a chance to review the questions I am going to ask you today and to give them some thought. I may ask questions that you have not reviewed to further clarify for me what you mean.

How would you describe the participants' reading and writing abilities? 
How would you describe each of their abilities to retell text orally and in writing?

Tell me about Juan's history of ADHD.

What are the school's goals for Juan as a special needs student?

Is there anything else that you would like to comment on?

Thank you again for taking time to talk with me today.

\section{Appendix B}

\section{Literacy Interview Questions for Student Participants}

I want to thank you for taking time to talk with me today. I will be recording what we say to help me remember our conversation.

I am interested to know how you feel about reading and writing.

Tell me about your reading.

Do you think of yourself as a good reader?

Who do you think is a good reader and why do you think so?

Tell me about your writing.

Do you think of yourself as a good writer?

Who do you think is a good writer and why do you think so?

Is there anything else you would like to tell me?

Thank you again for taking time to talk with me today.

\section{Appendix C:}

Retelling Interview Questions for Student Participants 
I want to thank you for taking time to talk with me today. I will be recording what we say to help me remember our conversation

I am interested to know how what you think about retelling.

Tell me about your oral retellings.

Tell me about your written retellings.

What really stands out to you as you think about the retelling sessions with your group?

Is there anything else you would like to tell me?

Thank you again for taking time to talk with me today.

\section{Appendix D}

\section{The Legend of Why the Iguana has a Double Tongue}

(Note: reprinted with permission from the Chamorro Studies and Special Projects Division, Guam Department of Education)

Many, many years ago in a deep and dark cave in the dense jungle of Guam, there lived an iguana. This iguana's mother was very proud of him. After all, he was a very strong and handsome iguana. After many months of motherly care and teaching, he was allowed to go into the jungle to look for some bird eggs, a great delicacy for any iguana. While the young iguana was walking in the jungle one day, he heard the voice of a mocking bird and said, "Hello! Where are you?" The mocking bird, however, flew away without answering. With that disappointment, the young, handsome iguana continued on his merry way, deeper into the jungle. It wasn't long before he met the bird known as the rail. After becoming friends, the iguana and the rail thought that what they needed was more color on their skin. They both decided that the rail would paint the iguana first. When the rail had finished painting the iguana with some bright new colors, the iguana was very pleased with his new appearance. He sang loud and long in his very melodious voice. The iguana then took the same paint brush that he was painted with and splattered the rail with spots. Becoming very angry, the rail said, "Because of this trick that you have played on me, your very pretty voice will become harsh and ugly." The rail pursued the iguana and struck him on the tongue, causing it to split into two parts. This is why the iguana, to this very day, has a forked tongue and the rail has spots all over his body. 